\title{
A True Human Tail in a Neonate Case report and literature review
}

"Mahesh K. Pillai ${ }^{1,2}$ and Smitha T. Nair²,3

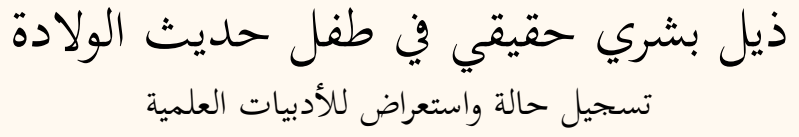

ماهيش كريشنا بيلاي وسميثا ثانكابـان ناير

ABSTRACT: A true human tail is a benign vestigial caudal cutaneous structure composed of adipose, connective tissue, muscle, vessels, nerves and mechanoreceptors. A true human tail can be distinguished from a pseudotail as the latter is commonly associated with underlying spinal dysraphism, which requires specialised management. True human tails are very rare, with fewer than 40 cases reported to date. We report a healthy one-day-old male newborn who was referred to the Bharath Hospital, Kottayam, Kerala, India, in 2014 with a cutaneous appendage arising from the lumbosacral region. Magnetic resonance imaging of the spine ruled out spinal dysraphism. The appendage was removed by simple surgical excision. Clinicians should emphasise use of 'true tail' and 'pseudotail' as specific disparate terms as the clinical, radiological and histological findings of these conditions differ significantly, along with management strategies and outcomes.

Keywords: Tail; Newborn; Magnetic Resonance Imaging; Spinal Dysraphism; Case Report; India.

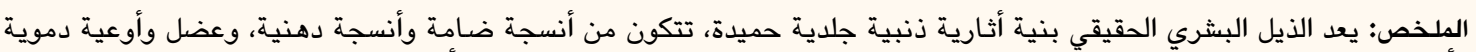

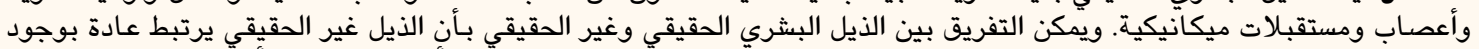

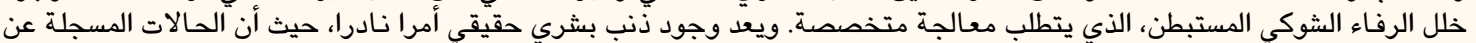

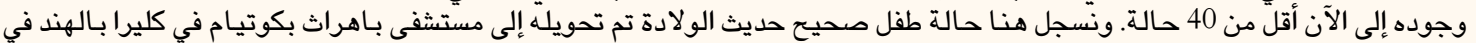

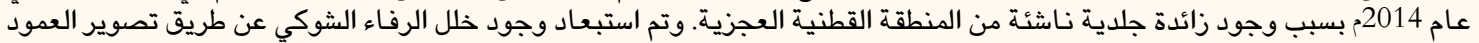

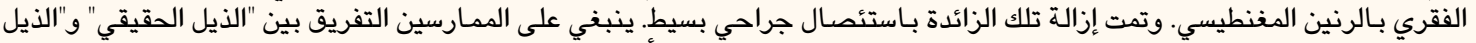

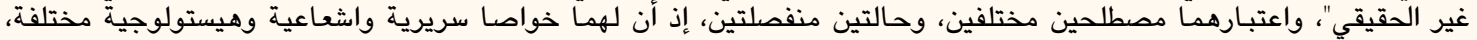

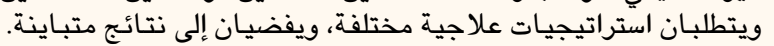
الكلمات المفتاحية: ذيل؛ حديث الولادة؛ التصوير بالرنين المغناطيسي؛ خلل الرفاء الشوكي؛ تقرير حالة؛ الهند.

A HUMAN TAIL IS A BENIGN CONGENITAL anomaly resulting in a vestigial lumbosacral dorsal cutaneous appendage which can be categorised as either a 'true tail' or a 'pseudotail' by clinical, radiological and histopathological examination. ${ }^{1,2}$ Unlike a true tail, a pseudotail indicates possible underlying spinal dysraphism and accurate distinction between these two entities is vital as both management and outcomes can vary. ${ }^{1-3}$ True human tails are very rare, with fewer than 40 cases reported to date. ${ }^{4}$ This case report describes an otherwise healthy neonate who was born with a true human tail.

\section{Case Report}

A one-day-old male neonate was referred to the Bharath Hospital, Kottayam, Kerala, India, in 2014 with a cutaneous appendage arising from the lumbosacral region which had been present at birth. He was the second child born to non-consanguineous parents and his sibling was clinically normal. The neonate had been born by vaginal delivery and the mother had had no history of illness, radiation exposure or drug intake other than vitamin supplementation during the antenatal period. In addition, there was no history of congenital anomalies in any of the family members. Apart from the appendage, the male newborn was otherwise healthy.

On examination, the neonate was observed to have a $6.5 \mathrm{~cm}$-long club-shaped soft tissue appendage arising and hanging down from the mid-sacral region, which was completely covered by skin and had no spontaneous movement [Figure 1]. The mass of the appendage was fleshy but firm and was not translucent. During palpation of the mass, the neonate cried when the appendage was pressed and cried even more loudly when it was pricked with a pin. The anal muscle tone was normal and the neonate had active movement in both lower limbs. A detailed examination revealed no other associated anomalies. 


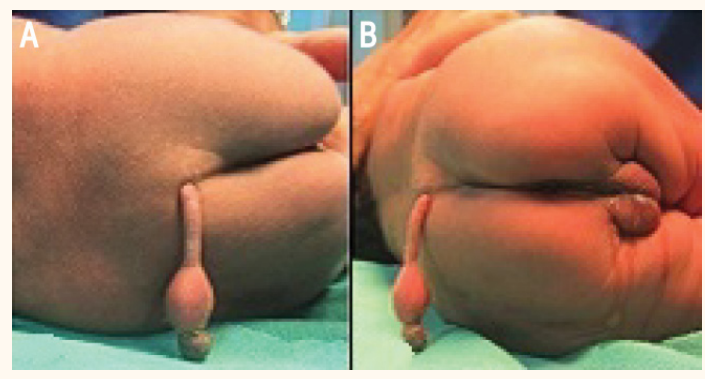

Figure 1: Clinical photographs of a male newborn showing a cutaneous appendage arising from the sacral region from the (A) frontal and (B) side views.

Magnetic resonance imaging (MRI) of the spine showed no evidence of spinal dysraphism, confirming the diagnosis of a true human tail [Figures 2 and 3]. The tail was excised by making an elliptical incision at the base. The wound was examined to rule out any connections between the tail and deeper structures which might not have been evident on the MRI scans. Microscopy of the excised tail showed that the tissue was lined by a squamous epithelium containing adipose tissue, muscle bundles, blood vessels and nerve bundles. The postoperative period was uneventful. At a one-month follow-up, the wound had healed well and a neurological examination was normal.

\section{Discussion}

In developing human embryos, a tail bud starts to develop during the fourth gestational week and grows unevenly for the next two weeks, extending and curling behind the hindgut. ${ }^{2,5-9}$ The proximal portion of the tail bud has 10-12 vertebrae, whereas the distal portion is composed of mesodermal elements without vertebrae. During the seventh and eighth gestational weeks, the proximal mesodermal elements retract into the soft tissue and the distal mesodermal

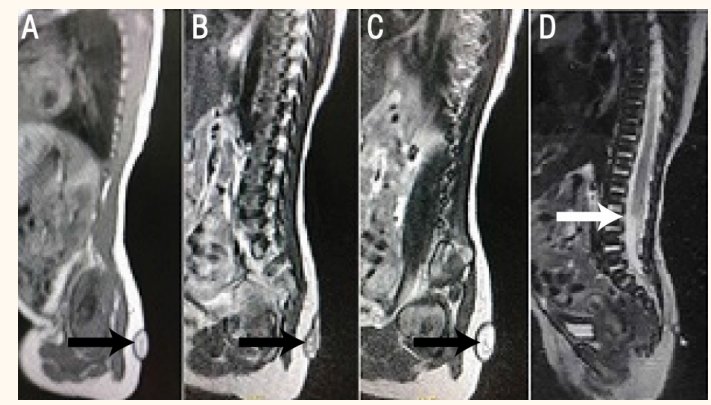

Figure 2: A-C: Sagittal T2-weighted magnetic resonance imaging (MRI) scans of a male newborn showing a pedunculated appendage (arrows) with fat intensity at the sacral region. D: Sagittal T2-weighted MRI scan showing the conus located at the level of the third lumbar vertebra (arrow).

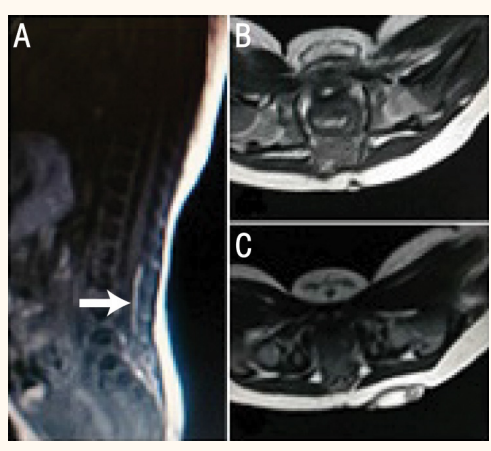

Figure 3: A: Sagittal T1-weighted magnetic resonance imaging (MRI) scan of a male newborn showing the thickened filum terminale with fat intensity (arrow). Axial (B) T1- and (C) T2-weighted MRI scans showing the origin of the appendage in the midline at the sacral level.

elements project outwards temporarily, before disappearing completely via apoptosis by the end of the eighth gestational week. ${ }^{2,5-9}$ According to $\mathrm{Lu}$ et al., the presence of a human tail is an abnormality in embryonic development, rather than a regression in the evolutionary process. ${ }^{2}$ In mice and other vertebrates, the genes that control the development of tails are the Wnt family member $3 A$ (WNT3A) and caudal type homeobox 1 genes; the downregulation of the WNT3A gene has been observed to induce apoptosis of the tail cells in mice. ${ }^{10-13}$ Therefore, it is possible that mutations resulting in increased upregulation of the WNT3A gene may result in retention of the embryonic tail in human newborns. However, further genetic research on this topic is necessary.

The presence of cutaneous midline congenital lesions in the lumbosacral region-such as vascular naevi, tufts of hair, dermal sinuses, subcutaneous lipomas, deviated gluteal furrows or a human tail-may indicate the presence of occult spinal dysraphism. ${ }^{1}$ A congenital cutaneous appendix arising from the lumbosacral region is referred to as a human tail. ${ }^{14}$ On histopathological examination, human tails can be classified into either true tails or pseudotails. ${ }^{1,15}$ A true human tail is a distal skin-covered boneless midline protrusion which is a remnant of the embryonic tail, composed of a core of striated muscle, adipose and connective tissue and containing blood vessels, nerve fibres, ganglion cells and mechanoreceptors, such as Pacinian corpuscles. ${ }^{4,15,16}$ True tails are commonly attached to the skin of the lumbosacral region; the skin which completely envelopes the mass is deficient in hair follicles and sweat and sebaceous glands., ${ }^{4,15,17}$ However, there is one case in the literature of a neonate born with a true tail which contained bone. ${ }^{18}$ True human tails are sometimes capable of spontaneous or reflexive motion, while voluntary contract- 
ions are rare. ${ }^{15,19}$ True human tails are not inherited; however, a single report has been published in which three female generations within one family were born with true human tails. ${ }^{20}$ The incidence rate of true human tails is twice as high among males in comparison to females. ${ }^{15}$

Unlike true tails, a pseudotail is a caudal protrusion composed of other normal and abnormal tissue such as bone, cartilage and remnants of notochord. ${ }^{3,15}$ During neurulation, non-fusion of the neural tube due to focal premature dysfunction can lead to the formation of a pseudotail. ${ }^{1}$ The non-fused neural tube exposes the paraxial mesoderm to the dorsal aspect of the neural ectoderm and induces the formation of fatty elements. This prevents neural tube fusion and the attachment of these fatty elements to the neural structures, which leads to a tethering cord and tethered cord syndrome. ${ }^{2}$ Early untethering of the cord is essential to prevent the development of catastrophic neurological sequelae. ${ }^{9,14,21}$ The incidence of cutaneous lesions along the craniospinal axis in the general population is approximately $3 \%$ and the most common lesions are deep dimples. ${ }^{22}$ However, cutaneous signs are present in $76 \%$ of patients with occult spinal dysraphism, including tails, dermal sinuses, lumbar lipomas, port wine stains, deviated gluteal furrows, hypertrichosis, haemangiomas and hamartomas. ${ }^{1}$ Lu et al. reviewed 59 patients with human tails and noted that $49 \%$ of cases had spinal dysraphism and $20 \%$ had tethered cords. ${ }^{2}$

\section{Conclusion}

The current case describes a neonate who was found to have a true human tail as evidenced by the absence of bony elements or underlying spinal dysraphism. It is very important that clinicians differentiate true tails from pseudotails as the latter entity is associated with underlying spinal lesions. Accordingly, MRI of the spine is crucial as it outlines the underlying pathology and helps in surgical planning. A true human tail is a benign condition and can be treated via simple surgical excision.

\section{References}

1. Guggisberg D, Hadj-Rabia S, Viney C, Bodemer C, Brunelle F, Zerah $M$, et al. Skin markers of occult spinal dysraphism in children: A review of 54 cases. Arch Dermatol 2004; 140:1109-15. doi: 10.1001/archderm.140.9.1109.

2. Lu FL, Wang PJ, Teng RJ, Yau KI. The human tail. Pediatr Neurol 1998; 19:230-3. doi: 10.1016/S0887-8994(98)00046-0.
3. Liaqat N, Sandhu AI, Khan FA, Ehmed E, Dar SH. Child with a tail. APSP J Case Rep 2013; 4:42. doi: 10.21699/ajcr.v4i3.69.

4. Shad J, Biswas R. An infant with caudal appendage. BMJ Case Rep 2012; 2012:bcr1120115160. doi: 10.1136/bcr.11.2011.5160.

5. Ledley FD. Evolution and the human tail: A case report. N Engl J Med 1982; 306:1212-15. doi: 10.1056/nejm198205203062006.

6. Zimmer EZ, Bronshtein M. Early sonographic findings suggestive of the human fetal tail. Prenat Diagn 1996; 16:360-2. doi: 10.1002/(SICI)1097-0223(199604)16:4<360::AID-PD857> 3.0.CO;2-U.

7. Hughes AF, Freeman RB. Comparative remarks on the development of the tail cord among higher vertebrates. J Embryol Exp Morphol 1974; 32:355-63.

8. Fallon JF, Simandl BK. Evidence of a role for cell death in the disappearance of the embryonic human tail. Am J Anat 1978; 152:111-29. doi: 10.1002/aja.1001520108.

9. Cai C, Shi O, Shen C. Surgical treatment of a patient with human tail and multiple abnormalities of the spinal cord and column. Adv Orthop 2011; 2011:153797. doi: 10.4061/2011/153797.

10. Greco TL, Takada S, Newhouse MM, McMahon JA, McMahon AP, Camper SA. Analysis of the vestigial tail mutation demonstrates that Wnt-3a gene dosage regulates mouse axial development. Genes Dev 1996; 10:313-24. doi: $10.1101 /$ gad.10.3.313.

11. Prinos P, Joseph S, Oh K, Meyer BI, Gruss P, Lohnes D. Multiple pathways governing $\mathrm{Cdx} 1$ expression during murine development. Dev Biol 2001; 239:257-69. doi: 10.1006/dbio. 2001.0446 .

12. Schubert M, Holland LZ, Stokes MD, Holland ND. Three amphioxus Wnt genes (AmphiWnt3, AmphiWnt5, and AmphiWnt6) associated with the tail bud: The evolution of somitogenesis in chordates. Dev Biol 2001; 240:262-73. doi: 10.1006/dbio.2001.0460

13. Takada S, Stark KL, Shea MJ, Vassileva G, McMahon JA, McMahon AP. Wnt-3a regulates somite and tailbud formation in the mouse embryo. Genes Dev 1994; 8:174-89. doi: 10.1101/ gad.8.2.174.

14. Kumar D, Kapoor A. Human tail: Nature's aberration. JJ Child Neurol 2012; 27:924-6. doi: 10.1177/0883073811428006.

15. Dao AH, Netsky MG. Human tails and pseudotails. Hum Pathol 1984; 15:449-53. doi: 10.1016/S0046-8177(84)80079-9.

16. Mukhopadhyay B, Shukla RM, Mukhopadhyay M, Mandal KC, Haldar P, Benare A. Spectrum of human tails: A report of six cases. J Indian Assoc Pediatr Surg 2012; 17:23-5. doi: 10.41 03/0971-9261.91082.

17. Belzberg AJ, Myles ST, Trevenen CL. The human tail and spinal dysraphism. J Pediatr Surg; 26:1243-5. doi: 10.1016/0022-3468 (91)90343-R.

18. Kabra NS, Srinivasan G, Udani RH. True tail in a neonate. Indian Pediatr 1999; 36:712-3.

19. Lundberg GD, Parsons RW. A case of a human tail. Am J Dis Child 1962; 104:72-3. doi: 10.1001/archpedi.1962.020800300 74010 .

20. Standfast AL. The human tail. N Y State J Med 1992; 92:116.

21. Amirjamshidi A, Abbassioun K, Shirani Bidabadi M. Skincovered midline spinal anomalies: A report of four rare cases with a discussion on their genesis and milestones in surgical management. Childs Nerv Syst 2006; 22:460-5. doi: 10.1007/ s00381-005-0014-2.

22. Powell KR, Cherry JD, Hougen TJ, Blinderman EE, Dunn MC. A prospective search for congenital dermal abnormalities of the craniospinal axis. J Pediatr 1975; 87:744-50. doi: 10.1016/ S0022-3476(75)80298-8. 